\title{
Escolarização da aritmética e produção de manuais escolares no Rio Grande do Sul no início do século 20
}

\author{
Teaching of arithmetics and school manuals production in \\ Rio Grande do Sul at the beginning of the 20th century
}

La escolarización de la aritmética y la producción de manuales escolares en Rio Grande do sul en el comienzo del siglo 20

CARMEN VIEIRA MATHIAS $^{1}$; ClAUdEMIR DE QUADROS ${ }^{2}$

\section{Resumo}

Por meio deste texto propõe-se a perceber como definições legais repercutiram na escolarização da Aritmética e na produção de manuais escolares no Rio Grande do Sul no início do século 20. Para tanto, dedica-se atenção ao que foi estabelecido no decreto n. 239 , de 5 de junho de 1899, por meio do qual se aprovaram os programas do ensino elementar e complementar para o Estado do Rio Grande do Sul, e a sua relação com um manual didático para o ensino de Aritmética publicado em São Leopoldo/RS, por Luís Schuler em 1904. Em termos gerais, percebeu-se que os conteúdos abordados no livro guardam estreita relação com o texto legal, apesar de pequenas incoerências.

Palavras-chave: História da Educação, Manuais Escolares, Ensino de Matemática, Aritmética.

\footnotetext{
1 Doutora em Matemática pela Universidade Federal do Rio Grande do Sul. Professor Associado na Universidade Federal de Santa Maria. E-mail: carmenmathias@ gmail.com.

${ }^{2}$ Doutor em Educação pela Universidade Federal do Rio Grande do Sul. Professor Associado na Universidade Federal de Santa Maria. E-mail: claudemirdequadros@gmail.com.
} 


\begin{abstract}
Through this text it is proposed to understand how legal definitions had repercussions in the teaching of Arithmetic and in the textbooks production in Rio Grande do Sul at the beginning of the 20th century. Therefore, attention is paid to what was established in act n. 239 of June 5,1899 , which approved the programs of elementary and supplementary education for the State of Rio Grande do Sul, and its relationship with a didactic manual for teaching Arithmetic published in São Leopoldo/RS , by Luis Schuler in 1904. In general terms, it was perceived that the contents covered in the book are closely related to the legal text, despite small disagreements.
\end{abstract}

Key-words: History of Education. School Manuals. Mathematics Teaching. Arithmetic.

\title{
Resumen
}

Por medio de este texto se propone percibir como definiciones legales repercutieron en el Rio Grande do Sul en el comienzo del siglo 20. Para tanto, se dedica atención a lo que fue establecido en el decreto n.239, de 5 de junio de 1899, por medeio del cual se aprobaron los programas de enseñanza elemental y complementaria para el estado de Rio Grande do Sul, y a su relación con el manual didáctico para la enseñanza de Aritmética publicado en São Leopoldo/RS, por Luís Schuler en 1904. En términos generales, se percibió que los contenidos abordados en el libro guardan estrecha relación con el texto legal, a pesar de pequeñas incoherencias.

Palabras-clave: Historia de la Educación. Manuales Escolares. Enseñanza de Matemática. Aritmética. 


\section{Introdução}

As referências ao ensino da Aritmética no Rio Grande do Sul têm um longo itinerário que pode ser percebido por meio da legislação. Neste contexto podem ser relacionadas a lei n. 14, Lei de Instrução Primária, de 1837; o Regulamento para as escolas públicas de instrução primária, de 15 de outubro de 1842; os Estatutos para o Licêo de D. Affonso na cidade de Porto Alegre, de $1^{\circ}$ de março de 1846; o Regulamento para a instrução primária e secundária da Província de São Pedro do Rio Grande do Sul; o Regulamento n. 6, de $1^{\circ}$ de junho de 1857; o Regulamento de 24 de janeiro de 1859; o Regulamento n. 48, de 26 de janeiro de 1859; o Regulamento do Curso de Estudos da Escola Normal de 1872, o Ato n. 1.072, de 1876, pelo qual a Assembleia Legislativa da Província definiu o Curso de Estudo da Escola Normal, o Regulamento da instrução pública primária de 1876; a lei n. 1.046, de 20 de maio de 1876; o Ato de 21 de agosto, pelo qual regulamentou-se a escola noturna provincial; a lei n. 1.340, de 27 de maio de 1881, o Regulamento da instrução pública; o Ato n. 141, de 30 de novembro de 1883, pelo qual se aprovou o programa de ensino público primário da Província; o decreto n. 89, de 2 de fevereiro de 1897, que reorganizou a instrução primária no Estado; o decreto n. 239, de 5 de junho de 1899, o decreto 1.575, de 27 de janeiro de 1910.

Neste artigo, pela sua relevância na estruturação do ensino primário no Rio Grande do Sul, dedicou-se atenção à relação entre o que foi proposto no decreto n. 239, de 5 de junho de $1899^{3}$, por meio do qual se aprovaram os programas do ensino elementar e complementar para o Estado, com um manual didático para o ensino de Aritmética publicado em São Leopoldo/RS, por Luís Schuler ${ }^{4}$ em 1904. A ênfase do texto recai, portanto, para a contrastação entre o proposto pela forma legal e os modos pelos quais isso foi apropriado num texto didático para uso escolar.

\section{Ensino de Aritmética no Rio Grande do Sul}

A definição dos programas do ensino primário elementar e complementar do Rio Grande do Sul, organizados pelo inspetor geral da Instrução Pública, Manoel Pacheco Prates, aconteceu em 1899. Transcreve-se, a seguir, o texto do decreto n. 239, de 5 de junho de 1899 , relacionados à prescrição dos conteúdos de Aritmética.

\footnotetext{
${ }^{3}$ Ver o texto completo em https://repositorio.ufsc.br/xmlui/handle/123456789/100095.

${ }^{4}$ Luiz Schuler nasceu em 28 de novembro de 1855 em Zweibrücken, na Baviera - Alemanha. Ingressou na congregação jesuíta em 3 de outubro de 1871, estudou Humanidades e Retórica em Wynandsrade e Filosofia em Blyendeck, na Holanda. Sua primeira vinda ao Brasil foi 1879 para atuar como professor de Filosofia e Matemática no Colégio Nossa Senhora da Conceição em São Leopoldo/RS. Em 1884 regressou à Europa para estudar Teologia na Inglaterra, em Ditton Hall. Ordenou-se em 1888 e voltou ao Brasil em 1889, novamente para o Colégio Nossa Senhora da Conceição de São Leopoldo. Atuou, ainda, em Pelotas, Rio Grande, Porto Alegre e Florianópolis. Nesta última cidade trabalhou na criação da Escola Diocesana São José, inaugurada em 15 de junho de 1915. Foi lente catedrático do Ginásio Catarinense, entre 1906 e 1925, e faleceu em 6 de agosto de 1925. Em vários textos é reconhecido pela sua obra social e designado como o apóstolo do bem. Empresta o nome ao Colégio Estadual Professor Padre Schuler, em Cocal do Sul, SC. Luiz Schuler publicou livros para o ensino de Aritmética, dos quais foram encontradas as seguintes referências: SCHULER, Luiz. Ensino de arithmetica: parte theorica - correcta e alterada. 3. ed. São Leopoldo: Thypographia do Centro, 1904. SCHULER, Luiz. Ensino de arithmetica. Porto Alegre: Selbach \& Mayer, s/d, 208p. SCHULER, Luiz. Ensino de arithmetica: parte theorica. 2. ed. Porto Alegre: Selbach \& Mayer, s/d, 208p. SCHULER, Luiz; BROWE, Pedro. Ensino de arithmetica: parte theorica / pratica. 4. ed. Porto Alegre: Selbach \& Mayer, s/d, 208p. SCHULER, Luiz. Elementos de algebra pratica: para uso das escolas complementares. Porto Alegre: Typografia do Centro, 1925. 53p.
} 


\section{Escolas elementares}

Primeira classe, Primeira secção

Arithmetica

Contar, sommar e subtrahir mentalmente no limite de 1 - 100, primeiro com o auxilio dos dedos, de pedrinhas, de grãos, etc., depois sem este auxilio.

Escrever os algarismos.

Contar, sommar e subtrahir mentalmente no limite de 1 - 100, sommando e subtrahindo numeros simples a numeros de dous algarismos.

Escrever os numeros de 1 - 100.

Sommar e subtrahir na lousa os numeros no limite de $1-100$.

Escrever os numeros de 1 - 1000.

Sommar e subtrahir na pedra os numeros compostos no limite de $1-1000$.

Primeira classe, Segunda secção

Arithmetica

Exercicios oraes sobre a taboada de multiplicação decorada.

Exercicios oraes de divisão no limite de 1 - 1000, deduzidos da taboada de multiplicação.

Exercicios de multiplicação e divisão na pedra dentro do limite de 1 - 1000.

Ler e escrever numeros compostos até 6 algarismos.

As quatro operações em numeros concretos sobre numeros até 6 algarismos.

Exercicios de calculo mental sobre as quatro operações.

Segunda classe, Primeira secção

Arithmetica

Desenvolvimento dos princípios da numeração decimal e sua applicação ás fracções decimaes.

Leitura e escripta das fracções decimaes.

As quatro operações em fracções decimaes.

Ler e escrever numeros inteiros de mais de 6 algarismos.

Systema metrico decimal, empregando, sempre que fôr possivel, o methodo intuitivo: metro, metro quadrado, metro cubico, litro grammo.

Leitura e escripta de numeros concretos, referindo-se a medidas do systema metrico.

Conversão de medidas em outras do mesmo systema metrico decimal.

Problemas praticos sobre as quatro operações em numeros inteiros e decimaes, applicando a redução á unidade.

Geometria Pratica

Noções de linha recta, curva e quabrada.

Rectas verticais, horizontaes e inclinadas.

Posições relativas das rectas: perpendiculares, obliquas e paralelas.

Noções do angulo. Distincção do angulo recto, agudo e obtuso.

Avaliação aproximada dos angulos, tomando por unidade o ângulo recto.

Pelo divisão do angulo recto em 2 e 3 partes iguaes, dar ideia de um angulo de $30^{\circ}, 45^{\circ}$ e $60^{\circ}$.

\section{Segunda classe, Segunda secção}

Arithmetica

Noções da divisibilidade de um numero por outro. Múltiplo e factor. Numeros primos. Caracteres da divisibilidade por 2, 3, 5, 9, 10 e 11. Menor multiplo commum. Maior divisor commum a dous ou mais numeros.

Fracções ordinarias. Ideia de metade, terço, quarto, etc., por meios intuitivos, fracção propria e impropria. Extracção de inteiros de fracções improprias e 
conversão de numeros mixtos em fracções improprias. Reducção das fracções ao mesmo denominador. Simplicação das fracções.

Propriedades geraes das fracções ordinarias. As quatro operações em fracções ordinarias.

Applicação das regras apreendidas em problemas praticos.

Conversão das fracções ordinarias em decimaes, e vice-versa. Fracções decimais periodicas.

Geometria Pratica

Noções de plano. Triangulos; sua divisão em equilateros, isosceles e escalenos.

Quadrilateros: trapezio e parallelogrammo; losangulo, rectangulo e quadrado. Polygonos regulares de mais de 4 lados.

Avaliação de áreas.

Terceira classe, Primeira secção

Arithmetica

Regras de tres simples e composta em problemas de applicação do methodo de reducção á unidade; primeiro em numeros inteiros, depois indistinctamente em inteiros, decimaes e fraccionarios.

Regra de juros simples em problemas practicos; avaliação dos juros, capital, taxa e tempo.

Ideia de accumulação de capital por meio de prestações em bancos e caixas economicas.

Regra de sociedade simples e composta, em problemas praticos e applicação do methodo de reducção á unidade.

Geometria Pratica

Circulo e circumferencia, sua distincção. Ideia pratica da relação constante entre o diametro e a circumferencia. Avaliação do comprimento da circumferencia e da área do circulo. Linhas e planos circulo: raio, diametro, corda, tangente, secante: segmento, sector corôa.

Terceira classe, segunda secção

Arithmetica

Quadrado de numeros inteiros, decimaes e fraccionarios.

Extracção de raiz quadrada de numeros inteiros, decimaes e fraccionarios.

Cubo de numeros inteiros, decimaes e fraccionarios.

Extracção de raiz cubica de numeros inteiros, decimaes e fraccionarios.

Problemas praticos com applicação da raiz quadrada.

Applicação da raiz quadrada em problemas geométricos: avaliação da hypotenusa num triangulo rectangulo, avaliação da área de triangulo, sendo dados os tres lados; avaliação do lado do quadrado, sendo dada a área; avaliação da área e do diametro, senda dada a área do circulo.

Geometria Pratica

Conhecimento pratico dos solidos geometricos: prisma, parallelipipedo, cubo, pyramide, cilindro, cone esphera.

Avaliação dos seus volumes e das suas superficies.

\section{Escolas complementares}

Primeira classe

Arithmetica

Theoria geral da numeração. 
Theoria das quatro operações fundamentaes em numeros inteiros.

Theoria da divisibilidade dos numeros; caracteres geraes de divisibilidade; caracteres particulares de divisibilidade.

Prova dos nove das quatro operações.

Theoria dos numeros primos.

Theoria do máximo divisor commum.

Theoria do menor multiplo commum.

Theoria das fracções ordinarias; propriedades, reducção ao mesmo denominar e a expressão mais simples; addição, subtracção, multiplicação e divisão.

Theoria das fracções decimaes. Propriedades; vantagens sobre as fracções ordinarias, addição, subtracção, multiplicação e divisão.

Conversão de uma decimal em ordinaria, e vice-versa.

Theoria das dizimas periodicas.

Theoria das fracções continuas.

Algebra

Noções preliminares. Valores numericos. Reducção de termos semelhantes. Operações algebricas: addicção, subtracção, multiplicação, divisão, potenciação, extracção das raizes de $2^{\circ}$ e $3^{\circ}$ grau.

Fracções algebricas. Reducção ao mesmo denominador: menor multiplo commum, reducção a expressão mais simples, maximo divisor commum.

Geometria Plana

Ideia de corpo, plano, linha e ponto.

Linhas: recta, curva e quebrada.

Angulos.

Theoria das perpendiculares e obliquas.

Theoria das parallelas.

Theoria dos triangulos.

Theoria dos quadriláteros.

Theoria dos polygonos em geral.

Theoria do circulo e da circumferencia.

Theoria das cordas, secantes e tangentes. Angulos inscriptos.

Theoria das linhas proporcionaes.

Theoria das figuras semelhantes.

Theoria das figuras equivalentes. Area dos polygonos.

Theoria dos polygonos inscriptos; avaliação das suas áreas e dos seus lados.

Theorema de Pythagoras.

Medida da circumferencia e área do circulo.

Calculo de Py.

Segunda classe

Arithmetica

Systema metrico decimal e comparação com o antigo systema brazileiro.

Numeros complexos. Conversão de um complexo em incomplexo e viceversa. Conversão de complexos em fracções e vice-versa. Addição, subtracção, multiplicação (partes aliquotas) e divisão de complexos.

Theoria da potenciação e da extracção de raizes: quadrado de um numero inteiro, decimal e fraccionario.

Extracção de raiz quadrada de um numero inteiro, decimal e fraccionario.

Cubo de um numero inteiro, decimal e fraccionario.

Extracção de raiz cubica de um numero inteiro, decimal e fraccionario.

Valores aproximados. Extracção de raiz quadrada e cubica com uma approximação qualquer. 


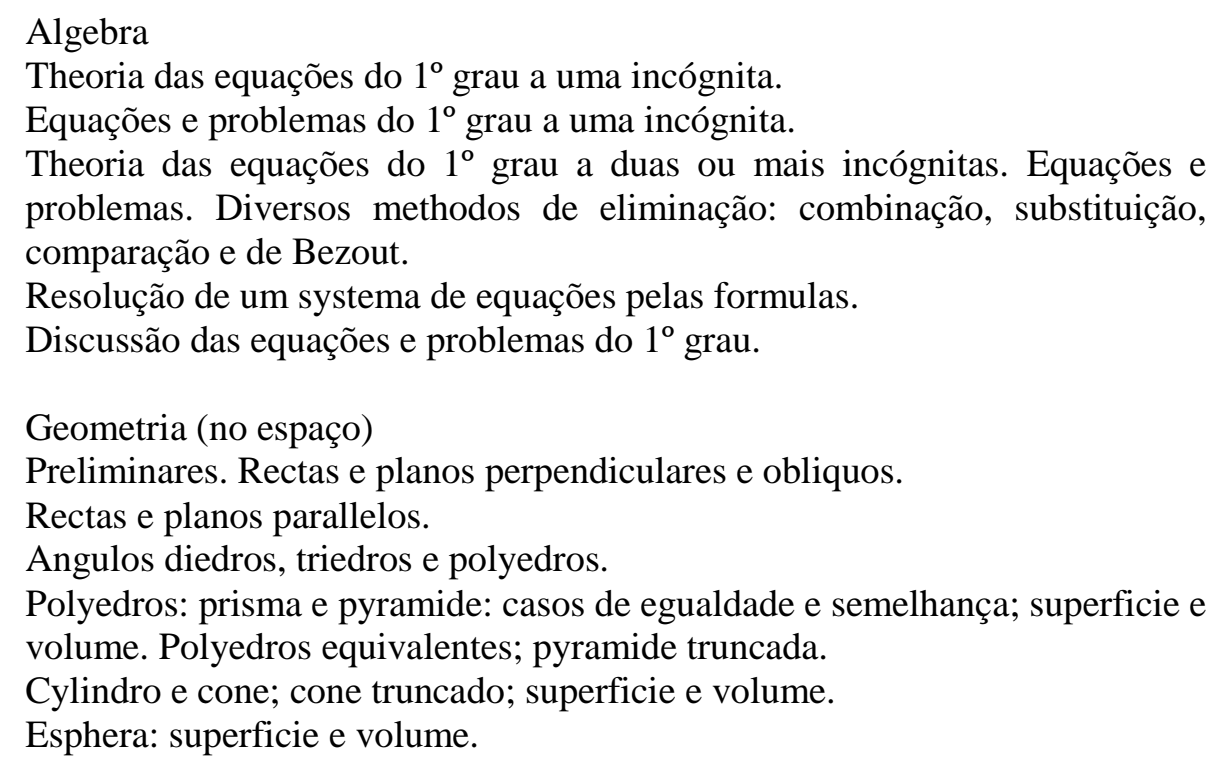

\title{
Terceira classe
}

Arithmetica

Theoria das razões, equidifferenças e proporções.

Aplicações praticas da theoria das proporções: regra de três simples e composta. Regra de juros simples.

Divisão de um número em partes directamente e inversamente proporcionaes. Applicaçoes praticas desta theoria: regra de sociedade simples e composta.

Regra de mistura e liga.

Theoria das progressões por differença e por quociente.

Theoria do s logarithmos. Uso das taboas. Exercicios praticos.

Juros compostos, annuidades, capitalisão e amortisação.

\author{
Algebra \\ Analyse indeterminada do $1^{\circ}$ grau. \\ Problemas indeterminados e sua discussão. \\ Equações e problemas do $2^{\circ}$ grau. \\ Equações biquadradas, reciprocas binomias. \\ Trigonometria \\ Preliminares. \\ Linhas trigonometricas. Relações entre as mesmas. Exercicios praticos. \\ derivadas. \\ Multiplicação e divisão dos arcos. \\ Uso das taboas de logarithmos das linhas trigonometricas. \\ Resolução dos triangulos rectangulos. \\ Resolução dos triangulos obliquangulos. \\ Ligeiras lições de agrimensura. (Leis, actos..., 1904, p. 260)
}

Theoria elementar das equações do $2^{\circ}$ grau. Formulas para a sua solução.

Seno, coseno e tangente da soma e differença de dous arcos; formulas

Observa-se que o programa versa sobre tópicos de Aritmética, Álgebra e Geometria. Porém, neste artigo preocupou-se em realizar a contrastação dos objetos referentes ao ensino de Aritmética, visto que as primeiras noções de Matemática são abordadas por essa via. Além disso, essas definições legais repercutiram, em particular, no ensino da Aritmética no âmbito de manuais escolares. Um dos exemplos disso é o livro Ensino de arithmetica: parte theorica, 
de Luiz Schuler, publicado em São Leopoldo/RS em 1904. O livro se apresenta no formato brochura, com capa dura, no tamanho 14 por $21 \mathrm{~cm}$, num volume único e se estrutura em oito capítulos, conforme descrito no quadro que segue.

Quadro 1 - Capítulos, temas e subtemas abordados no livro Ensino de arithmetica: parte theorica, de Luiz Schuler, 1904.

\begin{tabular}{|l|l|l|}
\hline \multicolumn{1}{|c|}{ Capítulo } & \multicolumn{1}{|c|}{ Tema } & \multicolumn{1}{c|}{ Subtemas } \\
\hline Capítulo 1 & Números inteiros & $\begin{array}{l}\text { Definições. Numeração. Operações. Divisibilidade dos } \\
\text { números. Números primos. Maior divisor comum e menor } \\
\text { múltiplo comum. }\end{array}$ \\
\hline Capítulo 2 & Frações & $\begin{array}{l}\text { Definições e propriedades das frações ordinárias. Operações } \\
\text { sobre as frações ordinárias. Frações decimais, frações } \\
\text { periódicas. Frações aproximadas e continuas. }\end{array}$ \\
\hline Capítulo 3 & Potências e raízes & $\begin{array}{l}\text { Operações sobre as potências. Extração da raiz quadrada. } \\
\text { Extração da raiz cúbica. }\end{array}$ \\
\hline Capítulo 4 & Medidas & $\begin{array}{l}\text { Sistema métrico. Sistema antigo. Números complexos. } \\
\text { Conversões de medidas. }\end{array}$ \\
\hline Capítulo 5 & Razões e proporções & Proporções propriamente ditas. Equidiferenças. \\
\hline Capítulo 6 & $\begin{array}{l}\text { Aplicações } \\
\text { proporções }\end{array}$ & $\begin{array}{l}\text { Regra de três. Regra de juro. Regra de desconto. Divisão } \\
\text { proporcional - regra de companhia. }\end{array}$ \\
\hline Capítulo 7 & Progressões & Progressões aritméticas. Progressões geométricas. \\
\hline Capítulo 8 & Logaritmos & $\begin{array}{l}\text { Definições e teoremas. Logaritmos vulgares. Construções de } \\
\text { tábuas de logaritmos. Uso das tábuas. }\end{array}$ \\
\hline Apêndice & & Regra de mistura e liga. Câmbio. \\
\hline
\end{tabular}

Fonte: Schuler, 1904.

Percebe-se que na primeira classe, primeira e segundas seções, de acordo com o programa que consta no decreto n. 239, existia uma preocupação com a idéia de contagem e a introdução das operações aritméticas. Observa-se que a primeira seção do capítulo 1 de Schuler (1904) apresenta definições precisas sobre quantidades, unidade e número.

Quanto à abordagem dos conteúdos, diferente do descrito no programa de 1899, percebe-se que o autor prima pelas definições. Essas são dadas de forma numericamente ordenada, a partir de itens. Na primeira seção do capítulo 1 o autor define número. Observa-se que este conceito está associado aos conceitos de quantidade e unidade, que são abordados na seção. O autor define quantidade, ou grandeza, como tudo pode aumentar ou diminuir e a classifica em dois tipos: contínua e descontínua. Apresenta a quantidade contínua como àquela que se pode decompor em partes tão pequenas quanto se queira, exemplifica que esta pode ser um pedaço de tempo e define as quantidades descontínuas como aquela que consta de unidades distintas. Como exemplo para esse tipo de quantidade apresenta um batalhão de soldados. Também define unidade como uma quantidade que serve para medir ou avaliar quantidades de mesma espécie. Encerra a seção apresentando a definição de Arithmetica como sendo a "sciencia dos numeros" (Schuler, 1904, p. 3).

Na segunda seção preocupa-se em definir sistema de numeração. Neste item o autor define numeração como "a arte de enunciar e escrever os numeros" (Schuler, 1904, p. 3) e 
divide-a em numeração falada e escrita. Afirma que o principal sistema de numeração é o decimal e apresenta os 10 algarismos que o compõem. Continua essa seção com o "principio da numeração falada" (p. 4) quando define ordens e classes. Para tratar das doze primeiras ordens da unidade o autor usa um quadro para representá-las, como ilustra a figura 1.

Figura 1 - Ordens da unidade.

\begin{tabular}{|c|c|c|c|c|c|c|c|c|c|c|c|}
\hline \multicolumn{12}{|c|}{ CLASSES } \\
\hline \multicolumn{3}{|c|}{$4 .^{\mathrm{a}}:$ BILLIÕES } & \multicolumn{3}{|c|}{ 3.a: MILHÕES } & \multicolumn{3}{|c|}{ 2.a: MILHARES } & \multicolumn{3}{|c|}{ 1. a UNIDADES } \\
\hline & & & \multicolumn{6}{|c|}{ ORDENS } & & & \\
\hline $12 . \mathrm{a}$ & $11 . \mathrm{a}$ & $10 .{ }^{a}$ & $9 . \mathrm{a}$ & $8 .^{a}$ & $7 . \mathrm{a}$ & $6 .{ }^{a}$ & $5 .^{2}$ & $4 .^{\mathrm{a}}$ & $3 . \mathrm{a}$ & $2 . \mathrm{a}$ & $1 . \mathrm{a}$ \\
\hline 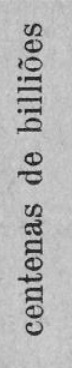 & $\begin{array}{l}0 \\
0 \\
\varrho \\
\Xi \\
0 \\
0 \\
0 \\
02 \\
0 \\
0 \\
0 \\
0 \\
0 \\
0\end{array}$ & 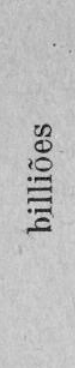 & 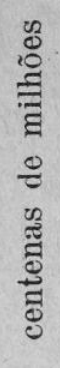 & 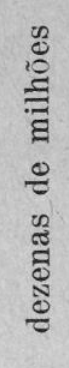 & 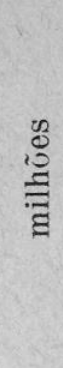 & 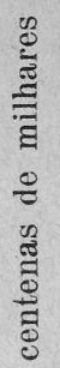 & 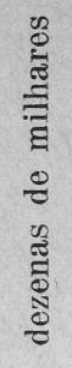 & 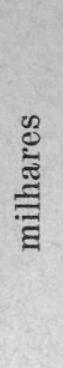 & 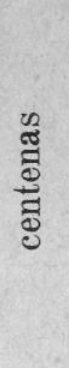 & 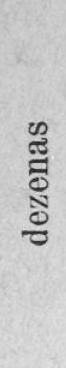 & 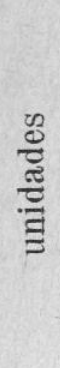 \\
\hline
\end{tabular}

Fonte: Schuler, 1904, p. 4.

Schuler (1904) aborda o "principio da numeração escripta" (p. 4) com o qual exemplifica o princípio apresentando como se escreve o número 8.043.705 e as ordens que os algarismos que o compõe pertencem. Apresenta os conceitos de valor absoluto e relativo, sem exemplificar. Também apresenta as consequências do sistema de numeração decimal, exemplificando que um número "torna-se 10, 100, 1000, etc. vezes maior ou menor acrescentando-se lhe ou suprimindo 1, 2, 3 etc zeros a sua direita" (Schuler, 1904, p. 4). Observa-se que essa é uma característica do sistema posicional de base 10, que o autor refere como sendo o "systema principal" (p. 4), porém, não exemplifica nem menciona a existência de outros sistemas de numeração.

No programa prescrito pelo decreto n. 239, é clara a observação de que o aluno aprenda a contar e depois a escrever os algarismos de 1 a 100. Essa preocupação é observada na obra analisada, visto que o autor expõe os algarismos do sistema decimal, apresenta classes, ordens e como devem ser lidos e escritos os numerais. $\mathrm{O}$ autor exemplifica a escrita de um número na classe dos milhões, porém, o programa, para a primeira classe, indica que na primeira seção essa deve ser de 1 a 100 e na segunda deve-se ler e escrever números compostos até seis algarismos, o que não é o caso do exemplo.

Quanto à abordagem das operações Schuler (1904) começa a seção 3 observando que "limitemo-nos a dar as definições das operações fundamentaes, supondo concluído o estudo exacto delas na aula primaria” (p. 5). Assim, apresenta definições para adição, subtração, multiplicação, divisão, potenciação e radiciação. Observa-se que o programa vigente trata das quatro operações em números concretos sobre números até seis algarismos. 
No que diz respeito às definições apresentadas no livro de Schuler (1904), apenas para as operações Potenciação e Radiciação constam exemplos. A operação Addição é definida da seguinte forma: “Addicionar ou somar é achar um numero que reúne as unidades de outros números dados" (p. 5). Define, ainda, os nomes dos termos dessa operação: "Ao resultado chama somma (ou total) e aos números dados dão as parcelas" (p. 5). Também define subtração como "achar uma parcela, sendo dada a outra parcela e a somma das duas" (p. 5) e assim como faz para a adição, o autor apresenta os termos dessa operação.

Nota-se a preocupação de Schuler (1904) em definir a soma utilizando a ideia de juntar duas quantidades dadas, porém, não menciona o fato de que a soma pode ser percebida como o ato de acrescentar uma quantidade inicialmente conhecida a outra dada. Define a subtração como a operação inversa a adição, sem nenhum comentário em que conjunto tal operação está de fato, que segundo a legislação deveria ser os números naturais. Observa-se que o autor não apresenta exemplos que permitam explorar os procedimentos de decomposição dos números: os famosos vai um e pedir emprestado, por exemplo. Acredita-se que, pela abordagem apresentada o livro, na época que era utilizado, não deveria ser adotado para o ensino da primeira classe, pois o último item do programa da Primeira Classe, Primeira seção é "sommar e subtrahir na pedra os numeros compostos no limite de 1 - 1000" (Leis, actos..., 1904, p. 260) ou, se adotado para essa classe, talvez não fosse o único texto.

Schuler (1904) define multiplicação da seguinte forma: "Multiplicar dous numeros é achar um terceiro que se forma do primeiro como o segundo se forma da unidade" (p. 5) e apresenta seus termos. Como faz para a subtração, define divisão como o inverso da multiplicação e também denomina os termos dessa operação.

$\mathrm{Na}$ sequência apresenta o que atualmente se denomina Expressões numéricas. É interessante observar que o autor define "parenthisis ou colchete como um signal ( ) ou [ ] que indica o todo com o qual se deve operar" (p. 5). Para essa definição apresenta dois exemplos, mas não faz indicação que existe uma ordem a ser respeitada em termos de sinais ou operações.

Ainda na seção Operações o autor apresenta alguns princípios relativos às operações. Esses princípios certamente correspondem no que o programa descreve como exercícios de cálculo mental sobre as quatro operações. Salienta-se que todos os princípios são acompanhados de pelos menos um exemplo.

A partir da análise das três primeiras seções da obra em comparação com o programa de 1899, acredita-se que essas serviram como revisão dos conteúdos trabalhados nas duas primeiras seções da primeira classe, visto a falta de exemplos. É interessante observar que o programa faz menção a "Exercicios oraes sobre a taboada de multiplicação decorada. Exercicios oraes de divisão no limite de 1 - 1000, deduzidos da taboada de multiplicação" (Leis, actos..., 1904, p. 262), porém, o livro não apresenta a tabuada, nem faz alusão a sua presença.

A quarta seção do capítulo 1 é destinada a divisibilidade de números. Schuler (1904) começa o capítulo definindo "numero primo, múltiplo, submultiplo e numeros primos entre si" (p. 7) e segue expondo os critérios de divisibilidade por 2, 3, 4, 5, 9, 11 e 25. Observa-se que os exemplos apresentados nos critérios de divisibilidade são trabalhados na perspectiva do sistema de numeração posicional de base 10 , conforme o princípio da numeração falada, apresentada na segunda seção da obra. $\mathrm{O}$ autor define que "um numero será divisível por um produto de factores primos entre si, quando fôr divisível por cada um deles" (p. 8) expandindo, dessa forma, os critérios de divisibilidade elencados. 
A quinta seção do capítulo 1 denomina-se Numeros primos e destina-se a apresentar quatro exemplos. O primeiro deles trata de determinar se um dado número é ou não primo. $\mathrm{O}$ segundo exemplo solicita determinar quais são os números primos até 51, utilizando o "crivo de Erastothesnes" (Schuler, 1904, p. 8). Apesar de não mencionar que se trata de um método prático para determinar números primos até certo valor limite, descreve os procedimentos de como realizar o algoritmo para chegar à solução do problema proposto. O terceiro exemplo mostra como se deve proceder para determinar os fatores primos de um número e o último exemplo mostra como determinar os divisores de um número. É interessante observar que, em ambos os casos, o procedimento é o mesmo utilizado nos dias atuais. Na sexta seção intitulada Maior divisor comum e menor multiplo commum o autor define "factor primo commum" e, a partir disso, define "o maior divisor commum (m.d.c.)" (p. 9). Define também múltiplo de dois números e, em seguida, define o "menor multiplo commum (m.m.c.)" (p. 10). Na sequência são apresentados três exemplos: o primeiro aborda como determinar o m.d.c. e o m.m.c. de três números. $\mathrm{O}$ segundo apresenta outro método para determinar o m.d.c e o terceiro outro método para determinar o m.m.c.

O segundo capítulo da obra denomina-se Fracções. Na primeira seção desse capítulo, denominada Definições e propriedades das fracções ordinarias, Schuler (1904, p. 11) define fração, numerador, denominador, fração própria e fração imprópria. Também apresenta sete propriedades sobre frações. A primeira e a segunda propriedades tratam de comparar frações com o mesmo numerador. A terceira propriedade define frações equivalentes. A quarta apresenta as frações como o quociente da divisão do numerador pelo denominador. Além disso, apresenta exemplos que envolvem números mistos e mostra como extrair inteiros de uma forma fracionária e o recíproco, como ilustra a figura 2.

Figura 2 - Redução de um número misto a uma fração e o reciproco.

Corollario. Para extrahir os inteiros d'uma fracção impropria, divide-se o numerador pelo denominador; o quociente completo representa aquella mesma fracção.

$$
\frac{38}{5}=38 \div 5=7 \frac{3}{5}
$$

Reciprocamento para REDUzIR um numero mixto Á FORMA FRACCIONARIA, multiplica-se o inteiro pelo denominador junta-se o numerador da fracção que conserva o mesmo denominador.

$$
8 \frac{3}{4}=\frac{8.4+3}{4}=\frac{35}{4}
$$

Fonte: Schuler, 1904, p. 12.

A quinta propriedade trata das alterações que uma fração sofre ao ter o mesmo número adicionado ao numerador e ao denominador. $\mathrm{O}$ autor percebe as alterações comparando a fração original com a unidade. A sexta propriedade apresenta exemplo de como simplificar uma fração. Não utiliza esse termo, apenas afirma que "para reduzir uma fracção mais simples, dividem-se os termos sucessivamente por seus divisores communs ou pelo m.d.c" (Schuler, 1904, p. 12). 
A última propriedade mostra como reduzir várias frações ao mesmo denominador. Observa-se que todas as propriedades são acompanhadas de exemplos e são necessárias para realizar operações com frações, assunto que foi tratado na seção dois, denominada Operações sobre as fracções ordinárias. Nessa seção o autor define as operações Addição, Subtração, Multiplicação e Divisão. Para todas as operações definidas são apresentados uma série de exemplos. No caso da operação adição, Schuler (1904) apresenta três exemplos, abordando a adição de frações com o mesmo numerador, com numeradores distintos e com números mistos. Para a operação subtração são apresentados cinco exemplos: um deles mostra a subtração de frações com mesmo numerador, outro a subtração de frações com numeradores distintos e os últimos três exemplos apresentam subtrações entre números mistos.

Na operação multiplicação Schuler (1904, p. 15) apresenta duas demonstrações, o que atualmente seriam exemplos, visto que não estão generalizando o pensamento, apenas apresentando a técnica, e também apresenta seis exemplos, sendo três sobre o produto de frações próprias e improprias e três acerca de números mistos.

Quanto à divisão de fração, assim como nas demais operações, é apresentada a técnica para determinar a solução, seguida de cinco exemplos: três exploram a divisão entre números fracionários e os outros dois a divisão de números mistos.

A terceira seção apresenta a definição de frações decimais, como se realiza a leitura de um número decimal e as operações acompanhadas de exemplos. A quarta seção do capítulo 3 aborda frações periódicas. Nessa parte Schuler (1904) trabalha as técnicas para converter uma fração ordinária em números decimal e vice-versa. Define fração decimal limitada, fração decimal periódica simples e fração decimal periódica composta. Na sequência apresenta algumas propriedades, designadas pelo autor de princípios, relativos à conversão das frações em decimais. Observe-se que nos dias atuais muitos desses princípios são apenas encontrados em livros de Cálculo Diferencial Integral.

A quinta seção apresenta o tópico Fracções approximadas e continuas. Diferente do que fez nos capítulos e seções anteriores, nessa seção o autor trabalha com três problemas para determinar aproximações de frações. Após apresentar a resolução dos problemas é que define fracções continuas e aproximadas (p. 23). Esse é um tópico que atualmente não é mais trabalhado em nenhum nível de ensino.

No programa prescrito pelo decreto n. 239, de 5 de junho de 1899 , a primeira seção envolve o Desenvolvimento dos princípios da numeração decimal e sua applicação ás fracções decimaes. Isso é contemplado pelo livro na seção 3 do capítulo 2. Nesse mesmo capítulo o autor apresenta Leitura e escripta das fracções decimaes e as quatro operações em fracções decimaes. Quanto ao restante dos tópicos elencados na primeira seção, são apresentados no quarto capítulo do livro.

Observa-se que as seções 4, 5 e 6 do primeiro capítulo da obra analisada são compatíveis com a segunda seção da segunda classe do programa em vigor na época. As seções supracitadas correspondem aos itens Noções da divisibilidade de um numero por outro. Múltiplo e factor. Numeros primos. Caracteres da divisibilidade por 2, 3, 5, 9, 10 e 11. Menor multiplo commum. Maior divisor commum a dous ou mais numeros descritos no programa.

Exceto a quinta seção, que trata das frações contínuas e aproximadas, o capítulo 2 se ajusta ao que é descrito no programa para parte da segunda seção. Nesse capítulo Schuler (1904) trabalha com as noções de fracções ordinárias, contemplando nos exemplos a idéia de metade, 
terço, quarto. Define fracção propria e impropria. A parte que trata de Extracção de inteiros de fracções improprias e conversão de numeros mixtos em fracções improprias é apresentada por meio de exemplos. A Reducção das fracções ao mesmo denominador, Simplicação das fracções e Propriedades geraes das fracções ordinárias são contempladas nas propriedades apresentadas na primeira seção. As quatro operações em fracções ordinárias são apresentadas na segunda seção. Quanto a Applicação das regras apreendidas em problemas práticos, o livro não apresenta nenhum problema da forma que conhecemos nos dias atuais, ou seja, com interpretação de um texto. Nesse caso, são apresentados exemplos de diferentes tipos, o que pode ser entendido como tais problemas. No que tange ao tópico Conversão das fracções ordinarias em decimaes, e vice-versa, o autor apresenta as definições e técnicas para trabalhar com esse tipo de situação. As Fracções decimais periodicas são apresentadas na seção 4.

O terceiro capítulo é iniciado com a apresentação de operações sobre potências (p. 24). Na primeira seção do terceiro capítulo são definidas as operações multiplicação e divisão de potencias de mesmo fator - o que nos dias atuais é denominado potências de mesma base - e é apresentado um exemplo para cada operação. $\mathrm{O}$ autor também define produto e quociente de potências semelhantes, de mesmo expoente, potência de potência e extração da raiz de uma potência, apresentando um exemplo para cada situação. Finaliza a seção definindo o quadrado e o cubo da soma e da diferença de dois números, apresentando exemplos para cada uma das definições.

A segunda seção se destina a apresentar o conceito de raiz quadrada, enfocando raízes exatas de números menores que 10.000, apresentando técnicas de como determinar a raiz quadrada de um número de dois ou mais algarismos, como ilustra a figura 3.

Figura 3 - Extração da raiz quadrada.

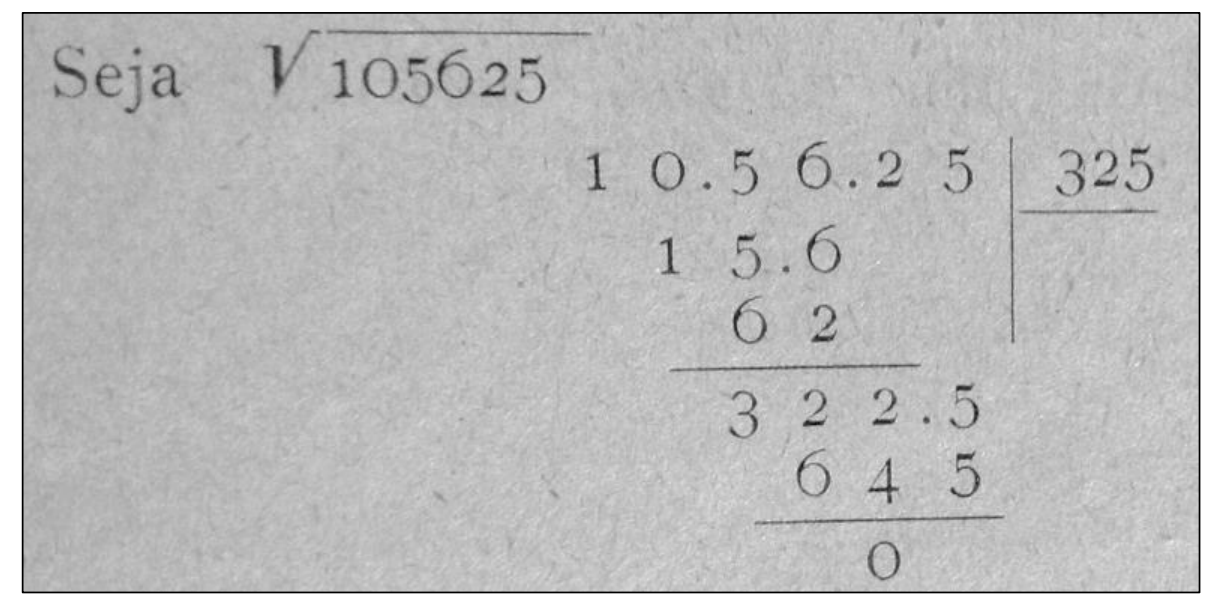

Fonte: Schuler, 1904, p. 27.

Na sequência, apresenta a técnica para extrair a raiz de um número fracionário e de um número decimal, via exemplo. Na terceira seção do capítulo 3 apresenta-se a extração da raiz cúbica. Do mesmo modo que realizado na seção anterior, o autor apresenta, a partir de exemplos, técnicas para a extração da raiz cubica de números inteiros decimais e fracionários.

É interessante observar que os conceitos de potência e raiz são apresentados na terceira seção do primeiro capítulo, onde o autor define as operações. As três seções do terceiro capítulo apresentam as propriedades oriundas dessas definições, o que está de acordo com o decreto n. 239/1899. No programa também constam problemas de aplicações, citando alguns exemplos, principalmente de cunho geométrico. Observa-se que o livro não traz nenhuma menção a essas aplicações. 
O quarto capítulo do livro é destinado ao tópico medidas, que consta no programa da segunda classe, primeira seção.

A primeira seção do capítulo 4 destina-se a definir sistema métrico: "é o systema de medidas e pesos que tem por base o metro" (Schuler, 1904, p. 29). Observa-se que a tabela contempla o que está descrito no programa como "Systema metrico decimal, empregando, sempre que fôr possivel, o methodo intuitivo: metro, metro quadrado, metro cubico, litro grammo" (Leis, actos..., 1904, p. 264). O autor não faz menção a números concretos, não contemplando o tópico Leitura e escripta de numeros concretos, referindo-se a medidas do systema metrico do programa.

$\mathrm{O}$ autor apresenta também um quadro de relações entre as medidas de peso, capacidade e volume, o que possibilita a transformação de uma unidade na outra, o que contempla o tópico Conversão de medidas em outras do mesmo systema metrico decimal do programa.

Figura 4 - Relações entre medidas.

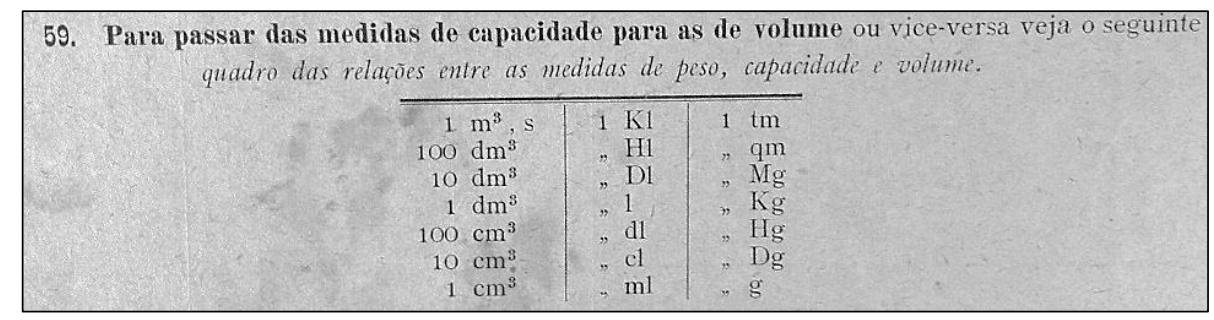

Fonte: Schuler, 1904, p. 31.

Schuler (1904) apresenta uma tabela denominada Tabela das relações entre as medidas do systema métrico e o antigo (p. 32). O sistema antigo ao qual se refere o autor é o que hoje conhecemos como sistema inglês de unidade. Segundo Rozenberg (2006) esse sistema foi adotado no Brasil Colônia. O sistema métrico decimal foi implantado no Brasil em 1862 pela lei imperial n. 1.157, mas em 1872 foram expedidas as instruções regulamentadoras da lei, instituindo nas escolas o ensino obrigatório do novo sistema. No que tange a comparação com o programa não é realizada menção a outro sistema que não o métrico decimal. Dessa forma, parece que o autor não é coerente com o estabelecido no documento oficial, uma vez que apresenta, ainda, ainda o sistema antigo.

Na terceira seção do quarto capítulo são apresentados os números complexos que, "no contexto do final do século XIX e início do século XX: é aquele número no qual constam espécies de unidades, dependentes umas das outras, segundo uma lei determinada. Por exemplo: 2 horas, 34 minutos e 15 segundos" (Souza Lobo, 1933, p. 2, apud Pais, 2010, p. 133). Atualmente, um número complexo é aquele da forma $\mathrm{z}=\mathrm{a}+\mathrm{bi}$, em que a e b são números reais e o símbolo $i$ representa a raiz quadrada da unidade negativa.

O programa aborda "Problemas praticos sobre as quatro operações em numeros inteiros e decimaes, applicando a redução á unidade” (Leis, actos..., 1904, p. 265), o que é contemplado na terceira e quarta seção do livro de Schuler (1904), que, apesar de trabalhar com algumas unidades do sistema antigo, apresenta exemplos de conversões de medidas nas quais há a necessidade de trabalhar com as quatro operações, tanto com números inteiros, quanto com números decimais. 
Observa-se que nessas duas seções, ao contrário do apresentado nos capítulos anteriores, a quantidade de exemplos é bem significativa, o que aproxima o livro dos materiais didáticos atuais.

No quinto capítulo apresentam-se os conceitos de Razão e proporções, que são fundamentais no entendimento dos conceitos de Regras de três simples e compostas, que são apresentadas no programa. $\mathrm{O}$ autor começa a primeira seção definido razão de dois números como o quociente de sua divisão e proporção como a igualdade de duas razões. Na sequência Schuler (1904) enuncia o Teorema fundamental das proposições e seu recíproco. Apresenta também as propriedades consequentes desses resultados e alguns exemplos. Na segunda seção do capítulo 5 o autor define equidifferenças que, segundo ele, são proporções impropriamente ditas e de pouco uso, como ilustra a figura 5.

Figura 5 - Equidiferenças.

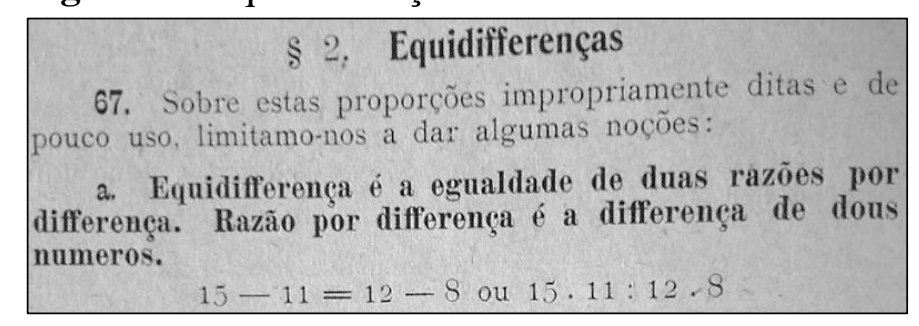

Fonte: Schuler, 1904, p. 40.

O sexto capítulo da obra é destinado a aplicações das proporções. A primeira seção destina-se a definir proporções diretamente e inversamente proporcionais. Observa-se também que o autor define a regra de três como um

problema no qual se procura um valor desconhecido por meio de três valores conhecidos de duas grandezas proporcionaes. A regra é directa quando as grandezas são diretamente proporcionaes, inversa quando as grandezas são inversamente proporcionaes, simples quando se consideram so duas grandezas e composta, quando se consideram mais de duas grandezas. (Schuler, 1904, p. 41)

Na sequência, apresenta três exemplos, um de regra direta, um de regra inversa e um problema que envolve regra composta. Observa-se que o autor faz uso do esquema de flechas, algo que ainda hoje é utilizado para resolver problemas de regra de três.

Figura 6 - Exemplos de regra de três.

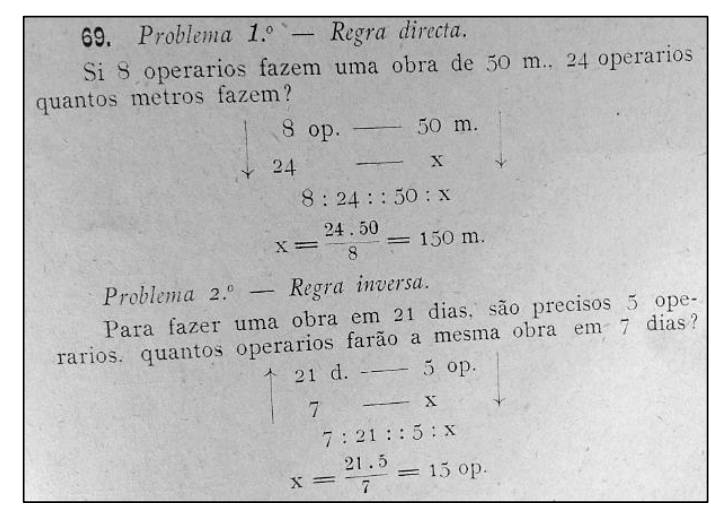

Fonte: Schuler, 1904, p. 41. 
Porém, o programa sugere que sejam trabalhados os conceitos de "Regras de tres simples e composta em problemas de applicação do methodo de reducção á unidade" (Leis, actos..., 1904, p. 270). Nesse sentido, o autor apresenta um exemplo do methodo da redução à unidade.

Figura 7 - Método da redução a unidade.

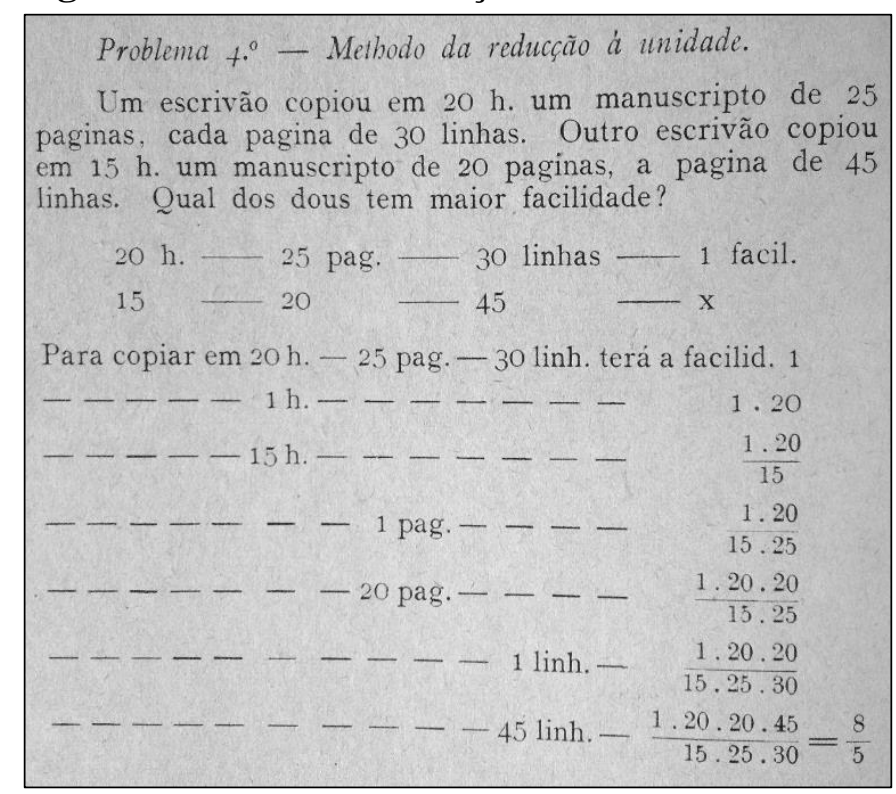

Fonte: Schuler, 1904, p. 42.

A segunda seção do capítulo 6 destina-se ao que o autor denomina Regra de juro, que define como "uma applicação da regra de três em que entram 3 grandezas proporcionaes: capital, juro e tempo" (Schuler, 1904, p. 44).

Apresenta um esquema de como armar as proporções e resolvê-las em relação ao juro, ao capital e ao tempo. Aborda, também, o conceito de juro acumulado: capital mais juro. $\mathrm{Na}$ sequência, apresenta oito problemas práticos que envolvem os conceitos de juro, capital, taxa, tempo e capital acumulado.

A terceira seção destina-se a apresentar o conceito de regra de desconto, definido como "um problema no qual se procura o valor actual duma divida ou lettra pagável no fim de certo prazo" (p. 45). São apresentados dois problemas, nos quais são trabalhados os conceitos de desconto por fora e desconto por dentro. Observa-se que essa seção contempla a legislação de 1899, que prescreve como pauta a "ideia de accumulação de capital por meio de prestações em bancos e caixas econômicas" (Leis, actos..., 1904, p. 271).

$\mathrm{Na}$ quarta seção o autor define divisão proporcional como "a repartição dum numero dado em partes proporcionaes a outros numeros dados" (Schuler, 1904, p. 47). Também define partes proporcionais e inversamente proporcionais, apresenta alguns exemplos e seis problemas. Os três primeiros destinam-se a repartir números naturais e decimais em partes proporcionais e inversamente proporcionais. O quarto e quinto problemas são de aplicações dos conceitos. Observa-se que na resolução dos problemas o autor emprega o método da redução à unidade. 
Antes de apresentar o último problema, define a regra da companhia, como "uma aplicação da divisão proporcional que tem por fim repartir os lucros ou as perdas proporcionalmente aos capitães e aos tempos durante os quaes estiveram empregados na empreza" (Schuler, 1904, p. 49). O sexto problema é uma aplicação dessa regra. Observa-se que essa seção contempla o que o programa descreve como regra de sociedade simples e composta. Ao concluir a análise dos capítulos 3 a 6 percebe-se que, com exceção da Applicação da raiz quadrada em problemas geométricos, o livro contempla todos os itens descritos no programa da segunda e terceiras classes.

Observa-se que nos quatro primeiros capítulos do livro são contemplados todos os itens descritos na primeira e segunda classes do programa. Os capítulos 5 e 6 abordam parte dos conteúdos da terceira classe, restando ainda os quatro últimos itens: regra de mistura e liga; theoria das progressões por differença e por quociente; theoria dos logarithmos. Uso das taboas. Exercicios praticos; Juros compostos, annuidades, capitalisão e amortisação.

A Theoria das progressões por differença e por quociente em Schuler (1904) é apresentada no capítulo 7, denominado Progressões. Na primeira seção o autor aborda o conceito de progressão arithmetica e a define como "uma serie de numeros dos quais cada um vale o seu precedente mais uma quantidade constante chamada razão" (Schuler, 1904, p. 50). Apresenta dois exemplos, explorando os conceitos de progressão crescente e decrescente. Enuncia e exemplifica quatro teoremas, que são as propriedades, oriundas da definição e apresenta três exemplos.

$\mathrm{Na}$ segunda seção, denominada Progressões geometricas, o autor define uma "progressão geometrica como uma "serie de numeros dos quaes cada um vale o precedente multiplicado por uma quantidade constante, chamada razão" (p. 51). Assim como na seção anterior, apresenta dois exemplos explorando os conceitos de progressão crescente e decrescente. Enuncia e exemplifica quatro teoremas, que são as propriedades, oriundas da definição e apresenta quatro exemplos. É interessante observar que o autor enuncia e realiza a demonstração do que conhecemos atualmente como a fórmula da soma dos termos e uma progressão geométrica, como ilustra a figura 8 .

Figura 8 - Soma dos termos de uma progressão geométrica.

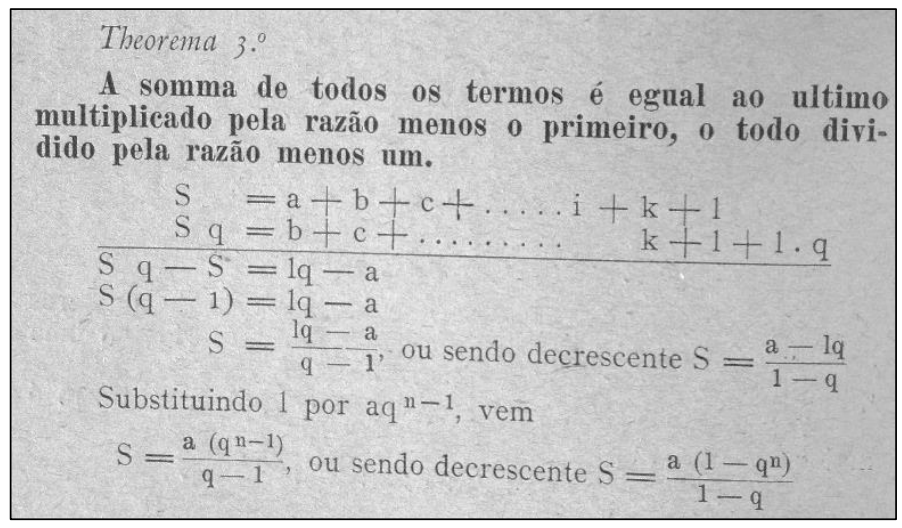

Fonte: Schuler, 1904, p. 52. 
Os tópicos Theoria dos logarithmos. Uso das taboas. Exercicios práticos do programa são abordados em Schuler (1904) no capítulo 8. Na primeira seção desse capítulo o autor define "logarithmos" como os "termos duma progressão arthmetica que começa em zero, correspondentes aos termos duma progressão geométrica que começa em 1" (p. 54). Na sequência, enuncia quatro teoremas que tratam das propriedades dos logaritmos.

A segunda seção do capítulo 8 denomina-se Logarithmos vulgares. Esse termo foi definido na seção anterior e segundo Schuler (1904, p. 55) os vulgares ou de briggs são os logaritmos que tem base 10. Atualmente esse termo não é mais utilizado.

Os primeiros conceitos explorados são os de característica e mantissa e apresenta, por meio de um exemplo, como reduzir um logaritmo de mantissa negativa a outros de mantissa positiva. Enuncia um teorema, que trata de propriedades da característica e apresenta quatro exemplos.

Define "cologarithmo dum numero" como o "logarithmo do numero inverso" (p. 56) e apresenta dois exemplos e propriedades associadas a esse conceito. Para finalizar a seção, o autor apresenta exemplos de operações sobre logaritmos. Na seção 3, denominada Construção das taboas de logarithmos, o autor apresenta três considerações de como se realiza a construção da referida tábua. A quarta seção trata do uso das taboas por meio de exemplos. Observa-se que o livro não traz a taboa, apenas apresenta exemplos de como utilizá-la. O último exemplo apresentado, como ilustra a figura 9, trata-se da resolução do que atualmente chamamos equação logarítmica.

Figura 9 - Equação logarítmica.

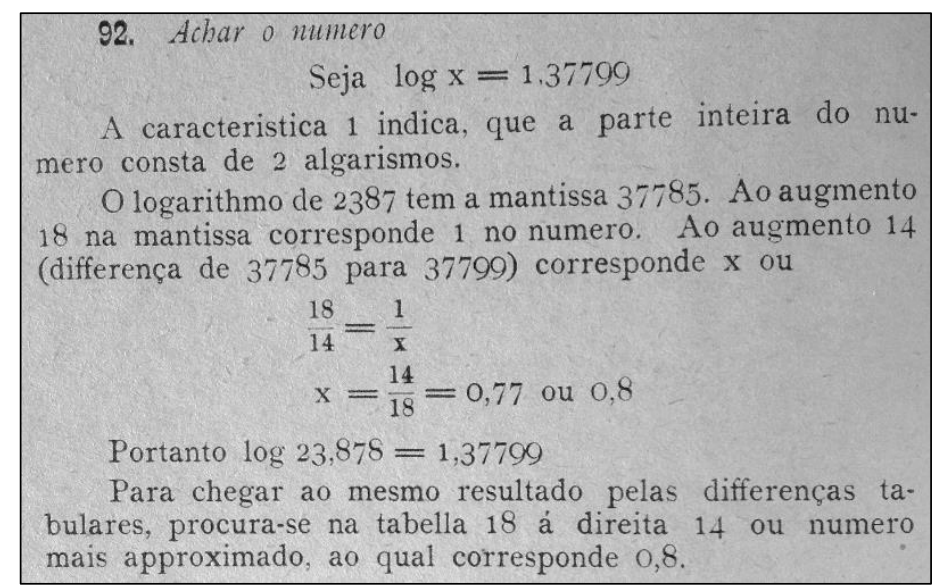

Fonte: Schuler, 1904, p. 58.

A obra apresenta ainda um apêndice, denominado Regra de mistura e liga. Na primeira seção do Appendice o autor afirma que a "regra de mistura tem por fim resolver os problemas que versam sobre a mistura de substancias susceptíveis de se reunirem" (p. 59). Segundo Schuler (1904) essa regra pode ser direta ou inversa e na sequência apresenta três exemplos práticos da aplicação da regra. Define regra de liga como "a regra das misturas aplicada aos metaes" e "título ou toque (ou quilate) duma liga" como "a relação entre o peso do metal puro e o peso total" (p. 59). Observa-se que essas regras são aplicações práticas do conceito de proporcionalidade. Na sequência é apresentada uma tabela da composição das moedas brasileiras e exemplos nos quais são determinados os quilates de uma liga e a composição de cada barra dependendo dos quilates. 
A segunda seção do apêndice trata do câmbio de moedas. O autor define câmbio como "1) a troca de dinheiro entre diversas cidades (interno) e paizes (externo), 2) o valor pago pelo dinheiro estrangeiro em nossa moeda" (p. 62). Apresenta uma tabela na qual a relação de alguns países, suas unidades monetárias e o valor da moeda daquele país em moeda brasileira.

$\mathrm{Na}$ sequência são apresentadas quatro situações em que é necessário realizar o câmbio e as respectivas resoluções. Observa-se que o conceito de cambio não é citado na legislação de 1899 .

\section{Considerações finais}

Realizada a descrição de todos os capítulos que compõe o livro de Schuler (1904) e comparado com as prescrições constantes no decreto n. 239 de 1899, pode-se apresentar um breve quadro comparativo no qual se elencam as classes e seções referidas na legislação, se o assunto foi ou não contemplado por Schuler (1904) e em qual capítulo se encontra.

Quadro 2 - Quadro comparativo entre o decreto n. 239 e o livro de Schuler.

\begin{tabular}{|c|c|c|c|c|}
\hline \multirow{2}{*}{ Classe/Secção } & \multicolumn{2}{|c|}{ Contemplado } & \multirow{2}{*}{ Capítulo } \\
\cline { 2 - 5 } & Sim & Não & Em parte & \\
\hline Primeira classe, Primeira secção & & & X & Capítulo 1 \\
\hline Primeira classe, Segunda secção & $\mathrm{X}$ & & & Capítulo 1 \\
\hline Segunda classe, Primeira secção & $\mathrm{X}$ & & & Capítulo 4 \\
\hline Segunda classe, Segunda secção & $\mathrm{X}$ & & & Capítulos 1 e 2 \\
\hline Terceira classe, Primeira secção & $\mathrm{X}$ & & & Capítulo 6 \\
\hline Terceira classe, Segunda seç̧ão & & & $\mathrm{X}$ & Capítulo 3 \\
\hline Escolas complementares, Primeira classe & $\mathrm{X}$ & & & Capítulo 2 \\
\hline Escolas complementares, Segunda classe & & & $\mathrm{X}$ & Capítulo 3 \\
\hline Escolas complementares, Segunda classe & $\mathrm{X}$ & & & Capítulo 4 \\
\hline Escolas complementares, Terceira classe & $\mathrm{X}$ & & & $\begin{array}{c}\text { Capítulos 5, 6, 7, } \\
8 \text { e apêndice }\end{array}$ \\
\hline
\end{tabular}

Observa-se que o decreto n. 239 prevê que na primeira classe/primeira secção o aluno deve aprender a contar e depois a escrever os algarismos de 1 a 100. Apesar de isso ser exposto em Schuler (1904), acredita-se que este contempla em parte o programa, pois existe certo nível de complexidade que, em geral, não é o concebido para uma primeira abordagem, pelo menos não nos dias atuais.

Acredita-se que os conteúdos abordados na segunda seção da primeira classe, bem como os da segunda classe, primeira e segunda seções, e os da primeira seção da terceira classe são totalmente contemplados pelo tex to didático.

Justifica-se optar por 'em parte' na segunda classe da terceira seção, pois Schuler (1904) não menciona Problemas praticos com applicação da raiz quadrada; applicação da raiz quadrada em problemas geométricos: avaliação da hypotenusa num triangulo rectangulo, avaliação da área de triangulo, sendo dados os tres lados; avaliação do lado do quadrado, sendo dada a área; avaliação da área e do diametro, senda dada a área do circulo, que são elencados na legislação de 1899. 
Quanto à opção realizada no item Escolas complementares-Segunda classe, observa-se que o livro não aborda valores aproximados - extracção de raiz quadrada e cubica com uma approximação qualquer - o qual é um dos itens para essa etapa proposto na forma legal.

Mas, apesar das diferenças percebidas e ressaltadas acima, percebe-se que o livro de Schuler (1904) foi estruturado a partir das perspectivas enunciadas na legislação, bem como tem o potencial de oferecer uma visão dos modos pelos quais a escolarização de saberes matemáticos foi pautada no âmbito da legislação e de manuais escolares do início do século 20 . Cabe ressaltar que o livro de Schuler (1904) oferece a possibilidade de promover formas de visibilidade de como os conteúdos e temas mudam ao longo do tempo e dos modos pelos quais a legislação participa desta mutação.

\section{Referências}

DECRETO n. 239, de 5 de junho de 1899. In: Leis, actos e decretos do governo do Estado do Rio Grande do Sul. 1899. Porto Alegre: Officinas Typographicas da Livraria Americana, 1904. Disponível em <https://repositorio.ufsc.br/xmlui/handle/123456789/100095>. Acesso em 23 fev. 2017.

PAIS, L. C. Traços históricos da aritmética nas últimas décadas do século XIX: livros didáticos escritos por José Theodoro de Souza Lobo. RBHM, v. 10, n. 20, 2010, p. 127-146.

SCHULER, L. Ensino de arithmetica: parte theorica - correcta e alterada. 3. ed. São Leopoldo: Thypographia do Centro, 1904. 